\title{
A Three-dimensional Classification System of Second Language Self-repair
}

\author{
Simin Zeng \\ School of Humanities and Social Sciences, Harbin Institute of Technology, Shenzhen, China
}

\begin{abstract}
Self-repair is the change(s) a speaker makes to his/her ongoing speech due to any concern in talk. Previous psycholinguistic taxonomies of self-repair regard it as manifestations of individual speech production problems. This study questions this stand by investigating the self-repair behaviour of English language learners from two secondary schools in China, examining their task discourse and stimulated-recall comments. The results enables a three-dimensional classification system that analyses self-repair with reference to 1) the change(s) involved in a self-repair that is reflected in a certain domain of language, 2) the strategy employed to make the change(s), and 3) the problem that prompts a speaker to self-repair. Analysis of the problems underlying the occurrences of self-repair demonstrates that L2 learners use self-repair to deal with problems in the interactions and the communicative contexts, in addition to their production problems.
\end{abstract}

Index Terms - self-repair, second language learner, learner discourse

\section{INTRODUCTION}

Self-repair, modifications made by a speaker to his/her prior speech, can be frequently found both in the everyday talk of first language (L1) speakers and in the talk of second language (L2) learners. When speakers encounter a problem in their L2 speech, they often self-repair - making changes to the form and/or the informational content of what they have said.

To study self-repair closely and systematically, taxonomies of self-repair have been built, mainly by psycholinguists (e.g., Levelt, 1983; Kormos, 1998, 2006). Researchers working within the psycholinguistic paradigm define self-repair as "surface manifestations of psycholinguistic processes" (Liskin-Gasparro, 1996, p. 318). The construct can include attempts by a speaker to rectify inappropriate or incorrect constructions in their utterances. In psycholinguistic research on L2 self-repair, learners' self-repairs are analysed to investigate the monitoring processes involved in the production of self-repairs and the underlying cognitive mechanisms (Kormos, 2006). The description of the monitoring processes and cognitive mechanisms are mostly based on Levelt's (1989) speech production model that was originally built to capture L1 speech production. Therefore, one salient feature of the research on L2 self-repair from the psycholinguistic perspective is its dependence on and extension of L1 self-repair research. This has resulted in a few problems of L2 self-repair classification systems. First, some of the learner-specific self-repair types established in L2 self-repair taxonomies cannot find their root causes in L1 speech production model. Second, by using L1 self-repair research as a starting point, researchers have overlooked the unique identity of L2 learners - that their understanding of "correctness" and "appropriacy", the two main causes of self-repair identified in past literature, might be different from L1 speakers'. Further, as learners, their speech context (e.g., school) might have a role to play in shaping their self-repair behaviour. Prior research on L2 self-repair has not addressed these problems.

This present study aims to fill this lacuna, by analysing speech data from learner-learner talk to describe how selfrepair can be identified and classified in a comprehensive and systematic manner. Classification of self-repair in this study does not follow previous systems of classification (e.g., van Hest, 1996; Kormos, 1998). It is built upon analysis of each individual case of self-repair yielded from the transcription of the recorded data. The different categories of selfrepair will be defined and portrayed based on the characteristics of the self-repair utterances identified to cluster within them. While describing the system of classification I have developed for my own project, I also, where relevant, draw critical comparisons with taxonomies used in prior studies in the repair literature. Under each category, examples from the data will be provided, followed by the speaker's stimulated-recall comments that contain evidence in support of its categorisation.

\section{Previous Classifications of L2 Self-RePair}

Self-repair is treated as the overt manifestation of self-monitoring - a component of the complete speech production system in the psycholinguistic perspective. Specifically, monitoring is a mechanism through which a speaker inspects their own speech (Hartsuiker \& Kolk, 2001), checks the correctness of their production in terms of grammatical rules and the appropriacy with reference to the context in which the language is used (Oomen \& Postma, 2001). Psycholinguistic researchers, thus, investigate the monitoring mechanism and attempt to provide insights into the different dimensions and stages of speech production. To reflect the language production system more closely, and to be 
more indicative of the functioning of the monitor, psycholinguists (Levelt, 1983; Kormos, 1998; van Hest, 1996) have worked on building classifications of self-repair.

\section{A. Problematising Self-repair Taxonomy Which Was Based on Psycholinguistic Model of Speech Production}

On the basis of Levelt's $(1983,1989,1993)$ speech production model, which is the most widely-adopted theory in self-repair studies, and depending on existing taxonomies of self-repair (Brédart, 1991; Levelt, 1983), Kormos (1998, 2006) identified instances of self-repair from recorded dialogue between L2 learners and herself, and distinguished between four main types of self-repair (see table 1). Psycholinguistic researchers tried to attribute each main type of self-repair to a certain mechanism in the speech production model, and reveal the root causes in speech production that could lead to the occurrences of self-repair.

TABLE I.

\begin{tabular}{|c|c|c|}
\hline \multirow{2}{*}{$\begin{array}{l}\text { Main classes of } \\
\text { self-repairs }\end{array}$} & \multicolumn{2}{|c|}{ Sub-types of self-repairs } \\
\hline & $\begin{array}{l}\text { L1 } \\
\text { (Levelt, 1993) (Brédart, 1991) }\end{array}$ & $\begin{array}{l}\text { L2 } \\
\text { (Kormos, 1998) }\end{array}$ \\
\hline $\begin{array}{l}\text { Different- } \\
\text { information repair }\end{array}$ & Different information repair & $\begin{array}{l}\text { Ordering error repair } \\
\text { Inappropriate information repair } \\
\text { Message replacement repair }\end{array}$ \\
\hline Appropriacy repair & $\begin{array}{l}\text { Appropriate level of information repair } \\
\text { Coherent terminology repair } \\
\text { Appropriate level of information and } \\
\text { coherent terminology repair } \\
\text { Repair for good language }\end{array}$ & $\begin{array}{l}\text { Appropriate level of information repair } \\
\text { Coherent terminology repair } \\
\text { Appropriate level of information and coherent } \\
\quad \text { terminology repair } \\
\text { Repair for good language } \\
\text { Pragmatic appropriacy repair }\end{array}$ \\
\hline Error repair & $\begin{array}{l}\text { Lexical error repair } \\
\text { Syntactic error repair } \\
\text { Phonological error repair }\end{array}$ & $\begin{array}{l}\text { Lexical error repair } \\
\text { Grammatical error repair } \\
\text { Phonological error repair }\end{array}$ \\
\hline Rephrasing repair & & Rephrasing repair \\
\hline
\end{tabular}

In Kormos's (1998) taxonomy, the first type of L2 self-repair - different information repair (D-repair), is a selfcorrection which modifies the content of the preverbal plan. In executing the second type of repair - appropriacy repair (A-repair), a speaker makes a correction to previously produced (1) inaccurate, (2) ambiguous, (3) incoherent or (4) pragmatically inappropriate language (Kormos, 1998, p.53). Based on the findings from L1 self-repair and monitoring, she argued that both D-repair and A-repair were due to errors in the conceptualising phase of speech production processes. The third type of repair - error repair (E-repair), is executed to attend to wrong linguistic items not in the conceptualiser, but in the formulator, during the course of message formulation. The last type of repair, Rephrasing repair (R-repair), is a repair type established by Kormos (1998) that reflects L2 speakers' incomplete knowledge of the target language. Though Kormos (1998) refined and modified Levelt's (1983) taxonomy of L1 self-repair to accommodate L2 learners' self-repairs and identified a learner-specific type of repair - R-repair, she did not pinpoint any specific mechanism underlying this R-repair. Therefore, whether this learner-specific type of repair is compatible with the native-speaker based speech production model remains a question.

Viewing self-repair as evidence of the mechanism of speech production, psycholinguistic researchers account for all self-repairs as products of an individual's language production system which is only relevant to the individual speaker's language ability (Kazemi, 2006), thus ignoring the interactional and contextual factors that can also affect self-repair behaviour. They have failed to take into account the nature of interaction in a learning environment, and only see the problems that can lead to self-repairs from the perspective of the speaker, not the other participant(s) in their learning environment.

Also, it is worth noting that, within this classification, the first three types can be identified in answer to a "why" question: why is a self-repair conducted. This can be due to a need to deliver different information, to alter inappropriate use of language, or erroneous productions. On the other hand, the fourth type of self-repair identified by Kormos, rephrasing repair, can be accounted for in answer to a "how" question: how is the uttered speech manipulated to produce a repair. Considering the inconsistency in the classification in Kormos's (1998) taxonomy, I find it necessary to examine other L2 self-repair classification systems for more information.

\section{B. Problematising Other L2 Self-repair Classification System}

Kazemi $(2006,2011)$ built a system of L2 self-repair classification by a bottom-up approach scrutinising every individual case of self-repair. Kazemi $(2006,2011)$ found that the cases of self-repair in his corpus clustered into five 
major categories: phonological repair, morphological/lexical repair, syntactic repair, context-oriented repair and information structuring repair. These five major categories of self-repair were primarily based on a "what" question: what domain of language is the repair focused on. Further, Kazemi (2006, 2011) identified five subcategories within each major category: inserting, deleting, reordering, replacing and abandoning. These five subcategories were termed "manner of repair" (Kazemi, 2006, p. 92). They are similar to the label of "rephrasing repair" in Kormos's (1998) taxonomy, all addressing a "how" question: how is a self-repair carried out.

However, some inconsistency exists in the case of context-oriented repair. Unlike the other four major types of repair that point to the domain of language where self-repair can take place, its label suggests the cause of trouble for repair the context. Defined as "changes brought about by the demand of the context in which speech takes place" (Kazemi, 2011, p. 98), this type of context-oriented repair does not specify the component of utterance it targets, and could overlap with the information structuring repair, both of which cab involve changes at the message level.

\section{Formulation of Research Questions}

Drawing on both Kormos's (1998, 1999a, 1999b) and Kazemi's (2006, 2011) findings and their respective problems, we can learn that, to build a reliable and comprehensive system of self-repair classification, the issues of "why" , "what", and "how", need to be taken into account. No taxonomy in existing repair studies was found to meet this requirement. At the same time, some of the definitions and criteria of identification of these three aspects were confusing.

Therefore, two research questions were formulated:

1. What are the main features of the self-repair behaviour of the L2 students?

This research question has a primarily descriptive aim, which is to scrutinise the self-repairs identified from the learners' L2 discourse, and to address the issues of how self-repairs lead to change(s) in certain domains of language .

\section{How do the students justify their use of self-repair, and how can their comments enable a comprehensive} understanding of L2 self-repair?

This question mainly concerns why self-repair is carried out. This question incorporates evidence from the learners' retrospective comments to explain the motivating factors for their use of self-repair. The problems that motivate students' self-repair behaviour will be identified and categorised.

\section{MATERIAL AND METHODS}

\section{A. Research Contexts and Participants}

This study was part of a larger study that took place in two high schools in southern China. At each school, six students of similar level of proficiency in English were recommended by their English teachers to participate in my study. The 12 participants were all first-year senior high school students, and had learned English for about eight years. When participating in this study, they paired up with their usual partners from their English classes. The participants are all anonymised in this study.

\section{B. Task as Data Collection Instrument}

The prior use of task shows that it can be a successful device to elicit spontaneous self-repairs from speakers. Kormos (1998, 1999a, 1999b) collected her data from task-based conversations between English learners and herself, who was a fluent speaker of English. In Kazemi's (2006, 2011) study, the learners' speech was recorded when they made presentations, which were monologues. None of them examined evidence of learner-learner talk, which could contain more problems that prompted learners to repair themselves. Four pair-work tasks were chosen as data collection instruments in this study. The tasks were checked by the teachers who confirmed that the design and contents fell within their students' competence. Students' task performance was captured by audio recorders.

\section{Stimulated-recall Interview: Transcripts and Recordings as Stimulus}

With the recorded learner discourse in the tasks constituting the primary data for analysis, students' own knowledge and perceptions of their cognitive processes were elicited through stimulated-recall interviews. The stimulated-recall interview method has been widely used in SLA research (Fincher, 2006) because 1) it enhances the vividness and accuracy of data through a stimulus, and 2) it examines the process of language use, rather than just language products (Gass \& Mackey, 2000). In this study, it was adopted to incorporate the students' own perceptions and interpretations of their self-repair behaviour for analysis.

In the two days following the students' completion of the tasks, I conducted a stimulated-recall interview with each pair of students. Arguably, there are limitations in not conducting the stimulated-recall interview immediately after the tasks, and the students might not have been able to accurately recall and report information on their own actions. Simpson, Eisenchlas and Haugh (2013) were faced with the same problem in their study. They compensated for this limitation by asking the students to only comment on the cases of self-repair that they felt they could remember and discuss. Their approach was borrowed in this study.

Before the interview, I transcribed their task discourse and made a preliminary note of the instances of self-repair. In the stimulated-recall interviews, I played a segment of a recording, and paused if the speaker noticed a change in his/her 
speech. This was usually featured by them giggling and repeating their speech in the recording. If the speaker did not notice his/her self-repair, I would replay and ask the speaker if I had heard and transcribed his/her speech correctly. My question, accompanied by the provision of a transcript, helped the students recall their thinking at the time of the task. After an instance of self-repair was identified, the student usually could, without prompts, start talking about the situation in which it had occurred and recall their thoughts at the time. Students' contributions during the stimulatedrecall interviews were recorded.

\section{Data Analysis}

Transcribing participants' talk was the first step in data analysis. When the students' task performance was being transcribed, CA transcription conventions (see Appendix A) were adapted for use to allow more detail to be included. For example, the length of pauses, discourse markers, changes in intonation and pronunciation, non-verbal expressions, like giggling, were all noted. In the next phase of transcribing the stimulated-recall interviews, as they were to be used for content analysis, only the content of speech in the interviews was transcribed.

Coding of self-repair started with the transcripts of students' task discourse, supplemented by transcripts of stimulated-recall interviews. Analysis of the stimulated-recall interviews first went through a process of data reduction: learners' comments on each instance of their self-repair were assigned to the transcription of task discourse in order to incorporate a personalised and contextual angle in understanding their use of self-repairs. The aim of this first cycle of reading and examining was open coding: "breaking data apart and delineating concepts to stand for blocks of raw data" (Corbin \& Strauss, 2008, p. 195).

With reference to the questions of "what", "how" and "why", three tree nodes are involved in this system: change, strategy and motivation. In further iterations with data, I assigned free nodes (child nodes) to excerpts. Some of these nodes were adapted from previous self-repair literature (e.g., van Hest, 1996; Kormos, 2008). Some were in vivo nodes emerging from the students' own comments, others were denoted by me. After all the identified cases of self-repair in the students' task discourse were coded, all the child nodes under the three tree nodes were compared and contrasted to enable revision of their definitions and refining of the overall classification system.

\section{Classifying L2 Self-RePAiR: Results AND Discussion}

As a self-repair occurs, the speaker's language production alters, and the difference(s), or change(s), can be manifested in a certain domain of language. This is made possible by the application of a strategy to the speaker's ongoing speech. The speaker uses a strategy to conduct a self-repair upon noticing a problem, which is the fundamental cause why the self-repair is conducted. Therefore, classifications of self-repair in this study are built according to a framework of three inter-related dimensions: change, strategy and motivation.

\section{A. Changes Involved in Self-repairs}

In past taxonomies (Levelt, 1983; van Hest, 1996; Kormos, 1998), researchers have delineated the different levels of language where self-repairs could occur, but only in the cases of error repairs. In this classification of self-repair, the change involved in a self-repair (i.e., at what level of language a self-repair occurs) is treated as an inseparable attribute of it. With an examination of all the cases of self-repair available in the data, the changes generated by self-repairs are found to occur in a number of aspects: (1) phonological, (2) lexical, (3) grammatical and (4) ideational.

1. Phonological change

The speaker makes a self-repair that is reflected in a change of phoneme.

(1) Helen: We are having an interview and (.) we are enthusiastic about (.) the project Maria: $\rightarrow \quad$ I think it is con confin convincing.

In the above example, Maria mistook the sound of /v/ for /f/ when she was trying to pronounce the word "convincing", and therefore made a phonological repair to correct it.

2. Lexical change

This refers to cases in which a self-repair shows itself as a change of a word or phrase, including both content words and function words.

(2) Tyler: $\rightarrow \quad$ Every year my sister feel very er exciting where when when er it comes to Halloween

In example (2), Tyler used an incorrect word to begin an adverbial clause. He repaired it and resulted in a lexical change.

3. Grammatical change

This means that the self-repair a speaker produces changes the case of a verb/noun, derivational morpheme, tense or aspect in his speech.

(3) Noarh: $\rightarrow \quad$ ok. It's like every parents loves every parent loves their baby

Here, Noarh was confused with whether "every" should be followed by a singular or plural noun form. In his second try, he repaired it, reflected in a grammatical change - from plural to singular.

4. Ideational change

This describes self-repairs that are represented as changes of the informational content of the speaker's speech. It can 
be a complete change of the speaker's preverbal plan (as in example 4), or just modification of the level of information without altering most of the content of the message (as in example 5).

(4) Helen: $\rightarrow$ um is there a plate that is er near er NO. is there a cup near the plate has nothing?

Retrospection: $\quad$ cuz I think we just talked about the plate so I want to change it to the cup.

In example 4, Helen made an ideational self-repair and changed her idea of what to express completely - by moving the subject of discussion from the plate to the cup.

(5) Nancy: $\rightarrow$ I can't stay with the people (.) stupid (.) more stupid than me because I will always make fun of them

Retrospection: $\quad$ because I was trying to say that people more stupid than me not just people stupid

Nancy introduced a comparative of the adjective, "stupid", to alter the level of information delivered in her message. Though it does not change the whole content, it can still be considered as a change of information.

\section{B. Self-repair Strategies}

Strategy is another facet of self-repair production. It describes how the speaker makes alterations to the problematic segment of speech, turns it into trouble-free language, and resolves the problem. The participants mainly used six strategies to conduct self-repairs in this study, namely, (1) deleting, (2) inserting, (3) replacing, (4) rephrasing, (5) recycling and (6) restarting. They will be detailed in the following.

1. Deleting

By applying the deleting strategy, the speaker removes a part of his uttered speech, without replacing it with an alternative. This is done by repeating the utterance with the deleted part missing.

(6) Tobin: she screamed help but Tyler was not at home. Em she took a taxi to em to the hospital immediately but there was a traffic jam. It took her half an hour and eventually when she er she reached the hospital and luckily er her baby was born (.) safely. at this point finally FINALLY Tyler appeared em.

Retrospection: I changed it to "finally" because I was going to say that "Tyler FINALLY" but I find it inappropriate to put it with "at this point" because "at this point finally" seems umm::

In example (6), Tobin was describing an imagined incident of Tyler's girlfriend. First, he attempted to use "at this point finally" to bring the story to its end, but very quickly, he repeated "finally", and this time, it was stressed. The stressed sound with the second "finally" can be seen as a symbol of the speaker restarting the sentence, retaining the use of "finally" and abandoning the previous head of sentence, "at this point". The speaker's retrospective comments also provide a clue that he changed "at this point finally" to "finally", therefore, employing the deletion technique by removing "at this point".

2. Inserting

This describes the strategy that a speaker adds a new bit of language to connect with the remaining part of speech and supplement the original meaning.

(7) Celia: $\rightarrow$ so I think why don't you choose (.) good health? It's I think it's so important

Retrospection: emm I think it's an individual:: emm:: (RE: opinion?) yeah. 'And does not

(8) Maria: represent other people,

Helen: lady gaga is wearing normal clothes so I feel very (.) you said what?

Maria: $\rightarrow$ Surprise

Retrospection: (:I think it's a mistake:)

(7) is an example of the speaker inserting a small phrase, "I think", to her original message. In this case, she did it to express her idea more accurately.

The inserting strategy has also been discussed in previous self-repair research. Van Hest (1996) created a category of "Appropriacy insertion repair" which he described as instances where "the speaker inserts one or more words to specify his message". Example (7) can fall into this category. However, van Hest (1996)'s classification and description has its limitations because (a) he limits the units that a speaker can insert to word(s), and (b) he limits the use of this strategy, inserting, to the purpose of a more precise message. Inserting can also work with units other than word(s) for other purposes. In example (8), Maria inserted a derivational morpheme to the word she just said - "surprise", to turn it into an adjective, for consideration of correctness.

3. Replacing

With this strategy, the speaker uses a substitute to replace an unwanted part of language in speech. The replacement is used to perform the role of the replaced part. In Schegloff's (2013, p. 43) language, the speaker conducts the replacing strategy while "retaining the sense that this is the same utterance".

(9) Chris: $\rightarrow$ em the man the man on the left er with a with the sunglass oh with the 
$\begin{array}{ll} & \text { glasses } \\ \text { Retrospection: } & \text { because it was wrong. Not sunglasses }\end{array}$

Chris replaced "sunglass" with "glasses" because he realised that "sunglass" was wrong and switched to a correct word.

In Van Hest's (1996) and Kormos's (1998) accounts, replacing was used by speakers to deal with nearly all kinds of concerns, as manifested in nearly all types of self-repair they described. Exceptions were van Hest's (1996) "appropriacy insertion repair" and Kormos's (1998) rephrasing repair that dealt with resource problems. In this paper, replacing is found to be employed by speakers to manage an even wider range of problems than they have reported.

(10) Irene: Is there a va/ei/se in front of the window

Noarh: Is there a what?

Irene: $\rightarrow \quad$ A va/ei/se. a VA/a:/SE (.) a va/a:/se. Do you know a vase?

Retrospection: Cuz I think British people is like they always say "va/a/se" but Americans say "valei/se" so I think this is a bit different and maybe he didn't understand what is "vase" so I change it to "va/a/se"

Here, Irene replaced the pronunciation of the vowel in "vase", /ei/, with /a:/. She made this replacement of a phoneme out of consideration for her partner's comprehension. Here, "replacing strategy" was applied to facilitate communication.

4. Rephrasing

This refers to the strategy that a part of a speaker's speech, be it completed or in progress, is formulated in a different way, while its intended meaning remains unchanged.

(11) Nancy: My dad gots a lot of (.) how to say s::(.) lots of problems with his health and:: because he is over 50 now and more. he is (.) but sometimes he acts or behaves like a 70s or maybe 60s and my mum finds it really annoying

Retrospection: I was trying to say the word but I can't find the word to complete the sentence so I change it

In example (11), Nancy tried to look for an adjective to describe the condition of her father, reflected by her retrospective comments and indicated by the pause after "he is". With the lexicon search unsuccessful, she resorted to the rephrasing strategy, to describe how her father looked.

Rephrasing repair, according to Kormos $(1998$, p. 63) is "revision of the preverbal plan by adding something or using paraphrase, because of uncertainty about its correctness, without changing the content of the original message". In her definition, she specified the form of a rephrasing repair - adding or paraphrasing, and the situations where rephrasing repairs would be used - when concerns for inadequate L2 resources arose. Though this is often the case, with (11) being an example, I find that speakers in this study also apply the rephrasing strategy in other contexts for other concerns. Example (12) will illustrate this.

(12) Maria: $\rightarrow \quad$ the second one I think it's (.) it should goes to a good listener

Helen: $\quad$ yah.

Maria: $\quad$ because * is very important in our daily life.

Retrospection: Erh first I want to say "I think it's good manner" and then I change my way to express myself (RE: even if there's no problem with the previous one?) yes (RE: so what made you change that?) emm:...:.: (RE: for good language) yeah!

In example (12), Maria paraphrased herself when she was trying to explain the choice she made in a discussion with her partner. Her use of the rephrasing strategy was not prompted by a linguistic problem. In the retrospective interview, when she could not find the right words to describe why she rephrased it, I suggested that it was for good language, because I felt that "it goes to" was a more sophisticated way of expressing it, and she confirmed my suggestion. This shows that the rephrasing strategy can be used to cope with problems besides limited resource in the target language.

5. Recycling

This is the strategy a speaker applies when he attends to a problem by shifting parts of his speech cyclically for the same purpose.

(13) Tobin:

one day Cathy felt a a extreme stomachache er (.) the the stomachache was long-lasting and so she searched on the internet for for the reason finally eventually she concluded eventually she made a conclusion she concluded that em her she's got pregnant. ((both laughed)) and:: she she screamed help but Tommy was not at home ((laughing))

Retrospection: I think she "eventually concluded" is not appropriate so so I changed it again and made it "she made a conclusion" and I find it hard hard* and changed back to she concluded

In example (13), Tobin had the problem that he could not discriminate between "finally" and "eventually", "concluded" and "made a conclusion". His way of confronting the problem was to recycle all the possible collocations he could think of to arrive at a better option for saying it. 


\section{Restarting}

This strategy describes how a speaker makes a conscious decision to produce his/her speech again. As a strategy, it differs from replacing in which a speaker rejects an element or elements of his speech, because of a problem with the replaced part of language, and substitutes it with a replacement to express the same meaning. With this strategy, the speaker restarts from the beginning, changes the meaning of his previous speech while keeping some elements of language unchanged.

(14) Tobin:

one day Cathy felt a a extreme stomachache er (.) the the stomachache was long-lasting and so she searched on the internet for for the reason finally eventually she concluded eventually she made a conclusion she concluded that em her she's got pregnant. ((both laughed)) and:: she she screamed help but tommy was not at home ((laughing)) let me do it again. Em em Cathy was pregnant and hahah one day she felt a discomfort in her stomach. So she researched on the internet for the reason. Suddenly em she got a severe stomachache. So she concluded that she her baby is coming out.

Retrospection: because I was trying to say that erh erh she's got pregnant for for about eight months like that. Because I thought that if she's just got pregnant she didn't have to rush the hospital and therefore she won't erh later the traffic jam. And she didn't need to scream help

Above is an example of the restarting strategy employed by a speaker who started his story again to make the story line right. What prompted him to use this strategy was not a problem that could be explicitly identified in his uttered speech, nor one that could be treated with actions towards particular elements of language. It was a problem with the discourse and its embedded logic, therefore, the speaker self-repaired by restarting his utterance.

\section{Motivations for Self-repairs}

Participants' self-repairs are motivated by 10 types of problems and concerns, including (1) resource; (2) planning; (3) correctness; (4) coherence; (5) preciseness; (6) appropriateness; (7) communication; (8) good language; (9) context; (10) others. In the following, they will be detailed with definitions and illustrated examples from the data.

1. Resource

This refers to problems caused by a speaker's limited resource of the target language. The problems can be due to the speaker lacking the knowledge to produce a word or a string of words (as in example 15), or feeling uncertain about the success of the planned or uttered speech (as in example 16).

(15) Helen: $\rightarrow \quad$ Sheldon is a scientist and I think he is a (.) he is always annoying his roommates.

Retrospection: I don't know the adjective of annoy so I say annoy is better

Above is an example of a resource problem in that the speaker did not know a certain lexical item and, therefore, had difficulties delivering the planned message. Helen wanted to describe Sheldon as an annoying scientist. However, the adjective of 'annoy', 'annoying', was not within her repertoire. With the problem pending, she abandoned the uncompleted half of the sentence and reattempted to construct the sentence with the verb form of 'annoy' in its present continuous tense, which expressed the meaning she intended.

(16) Renee: What colour of the cups or the bottle on the desk

Nancy: $\rightarrow \quad$ two black ones (.) and the cups they have (.) er they are exactly the same. the cups

Retrospection: I wanted to say "same pattern" but I am not sure "pattern" is the proper word here so I think maybe I can say it in another sentence

Example (16) shows another case of resource problem. The speaker was unsure whether the planned expression, "have the same pattern", would be proper. Consequently, Nancy paraphrased her meaning by saying "they are exactly the same".

Kormos's (1998) rationale for "rephrasing repair" is similar to the resource problem in that it acknowledges that in some cases L2 speakers are unsure of the accuracy of their utterances due to limited L2 competence. However, it is different from the resource-motivation class of repair because of their different angles of classifying self-repairs: the classification of "resource-motivation" focuses exclusively on the motivating factor of a self-repair while "rephrasing repair" describes a self-repair from all angles (i.e., features that have been be discussed earlier in this paper: strategy and change).

2. Planning

My application of the term "plan" draws on van Hest's (1996) concept of "conceptual plan" in relation to speech. He reported that wrong conceptual plans could result in self-repairs, in which case, "speakers selected the correct words for the concepts they wanted to express but that those conceptual plans turned out to be wrong" (1996, p. 41).

In my discussion of planning, I focus on two interrelated concepts: a wrongly conceptualised plan and inadequate planning. In the case of a wrong conceptual plan, speakers start speaking with a wrong idea. Though they have chosen the correct words to represent their idea, they have to amend their idea upon realisation that it is not right. Their 
amendment of the idea takes the form of self-repair. In the case of inadequate planning, as in the example below, there are times when speakers have not figured out what exactly to express before they speak and develop their plan in the course of speaking. The development of a plan can interfere with his/her speaking process, which results in self-repairs.

(17) Robot: $\rightarrow$ my friend told me a er my friend had a had a (.) my friend traveled to another country, and when he came back he described he described about er he described his journey.

Retrospection: (:没想清楚就说了:) (I haven't thought it through when I said it)

Example (17) shows that the speaker did not have a clear idea or plan of what he wanted to say when he began to speak, and needed to repair his speech as he developed his idea.

3. Correctness

This describes problems of language that the speaker considers incorrect. The standards by which an L2 speaker's oral production is judged are not exactly the linguistic rules of the target language. As learners, their knowledge of the L2 is under development, and some of the rules of L2 use that they have built are defective. Therefore, what they decide to correct are utterances that violate the speakers' perceived rules of correctness (as in example 19), not necessarily the actual rules of the language.

(18) Renee: then um (.) and the marriage if your if you have different VERY different $\rightarrow \quad$ backgrounds that means that your relationship may be unequally (.)

Retrospection: $\quad$ adverb and adjective

In example (18), Renee wrongly connected an adverb to the linking verb. Upon realising the problem, she paused briefly, and replaced the wrong word with a correct one.

(19) Meryl:

suddenly she found a mobile phone under the tree and she run towards it and picked it up. to her surprise the mobile phone worked. so she tried to er $\rightarrow \quad$ connect out of er outside but at last she failed

In example (19), Meryl was trying to describe a woman who got lost in a forest and found a mobile phone and tried to contact the outside world. To express this, she used "connect out of" in the first place. Her hesitation immediately after that and the following change of "out of" to "outside" evidenced her realisation that the previous use of "connect out of" was not right, and her attempts to repair the problem. Though the result of this, "connect outside", was not a fully correct expression with regard to the English language, it qualifies as a "self-repair" because it was what the L2 speaker resorted to when she confronted a problem, and represents the learner's current notion of correctness within her available L2 resources.

In prior analyses and categorisations of self-repair, the problem of incorrectness is the most frequently cited reason for the occurrences of self-repair. Examples are the category of error repair (E-repair) in both van Hest's (1996) and Kormos's (1998) systems of classification. Kormos (1998) contended that L2 speakers used E-repair to correct phonological, lexical and grammatical errors. Van Hest (1996) reported that speakers attended to phonological, morphological, lexical, tense/aspect, syntactic and conceptual errors with E-repairs. In this current classification, the "correctness-motivation" category includes all the types of problems identified by van Hest (1996) and Kormos (1998) as leading to E-repairs, except for the problem of conceptual errors, which falls under the "planning-motivation" category instead. Apart from this, the correctness-motivation category differs from the E-repair category as it is broader and includes self-repairs that L2 speakers conduct to meet their perceived standards of correctness, which are not always of native speaker standards.

4. Coherence

This refers to problems of incoherent uttered speech. In communication, an L2 speaker attends to what he himself has said, what he will say, and what the other party in the conversation has talked about. When they feel that what they are saying is or risks seeming inconsistent or illogical in relation to what is said before and after, they make a repair motivated by a concern for coherence.

(20) Tobin: and:: they're:: wa* (.) about five cups? And a teapot

Tyler: $\rightarrow \quad=$ yah. The old lady was er was you know pouring the water tea

Retrospection: because he said it's a tea pot

The context in example (20) is that Tobin and Tyler were describing two very similar photos. Following his partner's description of the teapot in his picture, Tyler carried on to talk about what an old lady was doing with the teapot in his picture. He made a self-repair by replacing "water" with "tea" because he felt that there was a problem of incoherence if "water" was poured from a "teapot".

Under the heading of "appropriacy repair" (A-repair) in Kormos's (1998) classification, there is a type of coherent terminology repair, which refers to self-repairs that a speaker carries out in order to correct incoherent choice of terminology. This is not the same as the "coherence-motivation" classification discussed here. In the data set of this paper, with respect to coherence, it is found that speakers are not only concerned about what terminology they use, but also the broader discourse, produced from both parties in a conversation, as shown in the example above.

5. Preciseness

This category refers to situations where the speaker judges that his language is not accurate, detailed, or specific 
enough, and makes alterations to his language to be more exactly and sharply stated.

(21) Chris: What did the cups look like?

Robin: three big cups was er (.) three big black cups and some (.) some pictures.

$\rightarrow \quad$ Maybe paintings

Retrospection: maybe using the word "picture" is not suitable emm:: pictures. "Picture"

is just like emm a photograph or some emm:: haha. Painting may be erh

erh more suitable for this

Above is an example of a self-repair produced to achieve preciseness. Robin opted for "painting" because he wanted to describe a painted picture and he felt that "picture" could imply that it was a photograph, and therefore, not conveying his exact meaning.

Problems of not-precise-enough language that could lead to self-repairs were discussed by van Hest (1996) and Kormos (1998). Van Hest (1996) talked about it only at the lexical level (termed as "appropriate lexical repair"), while Kormos (1998) only saw it happening at the ideational level where "the speaker decides to provide further details when the original message has not been precise enough" (termed as "appropriate level of information repair") (1998, p. 55). In this current system of classification, problems that lead to both "appropriate lexical repair" (van Hest, 1996) and "appropriate level of information repair" (Kormos, 1998) are both grouped under the preciseness-motivation class.

6. Appropriateness

This refers to the speakers' concerns for more proper language with regard to the situation referred to in their talk. When they speak, they sometimes feel that the word(s) they use have too strong emotional connotations and they would change for another one that can fit with the situation more appropriately.

(22) Noarh: I prefer advisor to listener

Irene: $\quad$ oh. Ok. (.) why?

Noarh: $\quad$ because if someone can only listen to you and say yes or I agree that's kind

$\rightarrow \quad$ of useless helpless

Retrospection: because "useless" "useless" is like em too hard for the situation (RE: too

harsh to describe a person?) yes

The "appropriateness-motivation" category is different from the category of A-repair included in all the past taxonomies of self-repair (Levelt, 1983; Brédart, 1991; van Hest, 1996; Kormos, 1998). In the above-mentioned systems, the standard against which "inappropriateness" was measured was not defined clearly. In the sub-categories of A-repair in these past taxonomies, only "pragmatic inappropriacy repair" (Brédart, 1991; Kormos, 1998) (self-repair utterances produced by speakers to rectify problems of language that is pragmatically unacceptable regarding the context of reference) is found to reveal some similarities with the "appropriateness-motivation" category in the current classification of self-repair.

7. Communication

This refers to the problems that a speaker feels hinder successful communication between himself and the interlocutor. This includes a speaker's worries that his uttered speech is confusing and might impede his interlocutor's comprehension. When there is no problem of misunderstanding or confusion, a speaker can also be motivated to conduct a self-repair if he believes that it can create more efficient communication and better cooperation between himself and the interlocutor.

(23) Celia: $\quad$ Popular too popular will maybe will attract others' attention. I just think

$\rightarrow \quad$ about it. So I think maybe familiar is enough. so:: what do you what's your reason?

Retrospection: em what do you think about it. But I but I if I just say "what do you think about it" maybe my partner will just express her opinion. But "what's your reason" is more directly

Example (23) shows an example of a speaker self-repairing for more effective communication. Celia was debating with her partner if being popular with friends and family was a necessary criterion for an ideal partner. After expressing her point of view, she invited her partner to give an opinion. While there was nothing wrong with her plan to say "what do you think", she worried that it might not be effective enough to elicit a developed argument from her partner, and, therefore, abandoned the initial question and produced a modified version. This type of self-repair is strong indication that self-repairs of L2 learners are not merely problems of their language production mechanisms, but also considerations of their communicative context and interlocutors.

8. Good language

The name and definition of this class of self-repair motivation is borrowed from Brédart (1991) and Kormos (1998). Brédart (1991) created the group of repair for "good language", but, in defining what language this particular type of repair is applied to, he did not distinguish between pragmatic errors and pragmatically acceptable language. Kormos (1998) made a distinction between these two and further explained the criterion of "repair for good language" as instances in which "the speaker judges to be not sophisticated enough according to his/her standard of eloquence" (1998, p. 58). Kormos's development of the definition "good language" was used in my study to categorise instances such as in the following example. 
(24) Meryl:

$\rightarrow$

I think the same hobby is very important

Retrospection: I want to say "you can talk more about this one" and I choose er "have

more topics". Because I think the er expression is better

Example (24) shows how a speaker conducts a self-repair out of consideration for good language. Meryl abandoned her previous plan to say "talk more about this one", though it was error-free, and substituted it with "have more topics to talk about" for she felt that the latter expression represented her idea better.

9. Context

This refers to contextual issues that prompt a speaker to modify his/her uttered speech. These context issues are embedded in the most relevant context of the speaker: for example, task requirements or task goal. Sometimes it is not until the middle of a speaker's speech that he/she realises or remembers that there is a need to adjust his/her language to attend to one or more context-relevant issues.

(25) Irene: $\rightarrow$ I'm full of pressure when I (.) when I did my homework yesterday (.) oh when I did yesterday's homework

Retrospection: because the object I mean the object on this paper is "yesterday's homework" but I said "homework yesterday". I just want to say the same thing in the paper

In the context of example (25), the task requirement was to make sentences with expressions given, one of which being "yesterday's homework". There was no problem with Irene's utterance, but she modified it when she realised that what she said did not correspond exactly to what was on the task sheet. Therefore, she repaired it by slightly changing her language to conform to the task.

This context-motivation category is similar to the category of context-oriented repair in Kazemi's (2011) study, which is repair conducted to attend to the demand of the context where the speech takes place. Both these two classes of self-repair are characterised by (1) the nonexistence of error, and (2) no change or very slight change of meaning. This type of self-repair shows that when learners conduct self-repairs, the problems they intend to address are not restricted to themselves.

\section{Others}

This includes problems that motivate the occurrences of self-repair but cannot fit into the above categories.

\section{CONCLUSION}

This paper provides a detailed rationale for the categorisation of identified L2 self-repair in this study. What constitutes the description and the classification of a self-repair are the three inter-related characteristics: change - in what domain of language a self-repair makes alteration(s); strategy - how a self-repair changes a speaker's speech and performs its "repair" function; motivation - what prompts a speaker to self-repair. These three dimensions, and the subcategories they subsume, form a three-dimensional classification system of self-repair. This classification system shows that the range of sources of prompt for L2 self-repair behaviour is not restricted to an individual's speech production problems. When repairing themselves, L2 speakers also show concerns for interactional and contextual issues, such as their interlocutors and the task demand. The strength of this categorisation system is that it is data-driven - developed on the basis of the participants' productions of self-repair. How different categories could be defined and delineated was also enabled by the participants' own comments on their self-repairs. Therefore, this self-repair classification system can capture the self-repair data in this study adequately and suit the further analytical needs of future self-repair studies. 


\section{APPENDIX A. TRANSCRIPTION NOTATION}

\begin{tabular}{|c|c|}
\hline THEY & Words in capitals indicate speaker emphasis. \\
\hline (.) & a short pause (less than 1 second) \\
\hline$(+)$ & 1-2 sec long pause \\
\hline$(++)$ & pause longer than 2 seconds \\
\hline$=$ & $\begin{array}{l}\text { Continuous utterances: when there is no interval between adjacent utterances, the } \\
\text { second being latched immediately to the first (without overlapping it), the utterances } \\
\text { are linked together with equal signs }\end{array}$ \\
\hline // & overlapping speeches of two speakers \\
\hline$((\quad))$ & $\begin{array}{l}\text { A description enclosed in a double bracket indicates a non-verbal activity. } \\
\text { Alternatively double brackets may enclose the transcriber's comments on contextual } \\
\text { or other features. }\end{array}$ \\
\hline (: well :) & $\begin{array}{l}\text { It means the speaker says what is inside the brackets and colons with laughter or } \\
\text { giggling. }\end{array}$ \\
\hline ? & $\begin{array}{l}\text { A question mark indicates a rising inflection. It does not necessarily indicate a } \\
\text { question. }\end{array}$ \\
\hline . & $\begin{array}{l}\text { A full stop indicates a stopping fall in tone. It does not necessarily indicate the end of } \\
\text { a sentence. }\end{array}$ \\
\hline$::$ & $\begin{array}{l}\text { Colons indicate that the speaker has stretched the preceding sound or letter. The more } \\
\text { colons the greater the extent of the stretching. }\end{array}$ \\
\hline ! & Exclamation marks are used to indicate an animated or emphatic tone. \\
\hline ، & Apostrophes indicate that the particular segment of speech was said in a low voice. \\
\hline bold & The bolded words mark sources of trouble and repairs \\
\hline$->$ & A line beginning with an arrow contains students' repair(s). \\
\hline$* * *$ & Asterisks stand for the presence of an unclear fragment on the tape. \\
\hline italics & Students' retrospective comments are italicised. \\
\hline RE & This is followed by questions or prompts made by the researcher. \\
\hline (translations) & $\begin{array}{l}\text { When the uttered speech is in Chinese, I provide the translations in the following } \\
\text { brackets. }\end{array}$ \\
\hline
\end{tabular}

\section{ACKNOWLEDGEMENTS}

This work was part of a larger project supported by Chinese Scholarship Council. The author wishes to thank Dr Michael Evans and Dr Yongcan Liu for their feedbacks and comments on earlier drafts of this paper.

\section{REFERENCES}

[1] Brédart, S. (1991). Word interruption in self-repairing. Journal of Psycholinguistic Research, 20(2), 123-138.

[2] Corbin, J., \& Strauss, A. (2008). Basics of qualitative research: Techniques and procedures for developing grounded theory. Thousand Oaks, California: SAGE Publications.

[3] Fincher, A. (2006) Functions of self-initiated self-repair in an advanced Japanese language classroom. PhD Dissertation, Griffith University.

[4] Gass, S. M., \& Mackey, A. (2000). Stimulated recall methodology in second language research. Mahwah, N.J.: Lawrence Erlbaum Associates.

[5] Hartsuiker, R. J., \& Kolk, H. H. J. (2001). Error Monitoring in Speech Production: A Computational Test of the Perceptual Loop Theory. Cognitive Psychology, 42(2), 113-157.

[6] Kazemi, A. (2006). A systematic study of self-repair in second language classroom presentation: with some reference to social variables and language proficiency. PhD dissertation. The University of New South Wales.

[7] Kazemi, A. (2011). An investigation into the relationship between the type of self-repair and structural complexity of utterances. International Journal of English and Literature, 2(4), 96-102.

[8] Kormos, J. (1998). A new psycholinguistic taxonomy of self-repairs in L2: A qualitative analysis with retrospection. Even Yearbook, ELTE SEAS Working Papers in Linguistics, 3, 43-68.

[9] Kormos, J. (1999a). Monitoring and Self-Repair in L2. Language Learning, 49(2), 303-342.

[10] Kormos, J. (1999b). The effect of speaker variables on the self-correction behaviour of L2 learners. System, 27(2), $207-221$.

[11] Kormos, J. (2006). Speech Production and Second Language Acquisition. Mahwah, NJ: Lawrence Erlbaum.

[12] Levelt, W. J. M. (1983). Monitoring and self-repair in speech. Cognition, 14(1), 41-104.

[13] Levelt, W. J. M. (1989). Speaking: from intention to articulation. Cambridge, Mass.: The MIT Press.

[14] Levelt, W. J. M. (1993). Language use in normal speakers and its disorders. In G. Blanken, J. Dittmann, H. Gimm, J. C. 
Marshall, \& C. W. Wallesch (Eds.), Linguistic disorders and pathologies. Berlin: de Gruyter, 1-15.

[15] Liskin-Gasparro, J. E. (1996). Circumlocution, communication strategies, and the ACTFL proficiency guidelines: An analysis of student discourse. Foreign Language Annals, 29(3), 317-330.

[16] Oomen, C. C. E., \& Postma, A. (2001). Effects of Time Pressure on Mechanisms of Speech Production and Self-Monitoring. Journal of Psycholinguistic Research, 30(2), 163-184.

[17] Schegloff, E. A. (2013). Ten operations in self-initiated, same-turn repair. In M. Hayashi, G. Raymond, \& J. Sidnell (Eds.), Conversational repair and human understanding (pp. 41-70). Cambridge: Cambridge University Press.

[18] Schegloff, E. A., Jefferson, G., \& Sacks, H. (1977). The preference for self-correction in the organization of repair in conversation. Language, 361-382.

[19] Simpson, R., Eisenchlas, S. and Haugh, M. (2013). The functions of self-initiated self-repair in the second language Chinese classroom. International Journal of Applied Linguistics, 23(2), 144-165.

[20] Van Hest, E. (1996). Self-repair in L1 and L2 production. Tilburg: Tilbury University Press.

Simin Zeng obtained her $\mathrm{PhD}$ in Second Language Education from the University of Cambridge. She currently serves as Assistant Professor at the School of Humanities and Social Sciences, Harbin Institute of Technology, Shenzhen, China. She is interested in researching issues in second language education, in particular, in a sociocultural approach. Her work mainly examines the evidence of L2 learners' self-regulation - their self-repairs, and seeks to explore pedagogical interventions that facilitate the growth of self-regulation from the perspective of dynamic assessment. 